\title{
On the dynamic behavior of three readily available soft tissue simulants
}

\author{
G. J. Appleby-Thomas, ${ }^{\text {a) }}$ P. J. Hazell, J. M. Wilgeroth, C. J. Shepherd, D. C. Wood, \\ and A. Roberts \\ Cranfield Defence and Security, Cranfield University, DA-CMT, Shrivenham, Swindon, SN6 8LA, \\ United Kingdom
}

(Received 15 September 2010; accepted 7 March 2011; published online 21 April 2011)

\begin{abstract}
Plate-impact experiments have been employed to investigate the dynamic response of three readily available tissue simulants for ballistic purposes: gelatin, ballistic soap (both subdermal tissue simulants), and lard (adipose layers). All three materials exhibited linear Hugoniot equations-of-state in the $U_{S}-u_{P}$ plane. While gelatin behaved hydrodynamically under shock, soap and lard appeared to strengthen under increased loading. Interestingly, the simulants under test appeared to strengthen in a material-independent manner on shock arrival (tentatively attributed to a rearrangement of the amorphous molecular chains under loading). However, material-specific behavior was apparent behind the shock. This behavior appeared to correlate with microstructural complexity, suggesting a steric hindrance effect. (C) 2011 American Institute of Physics. [doi:10.1063/1.3573632]
\end{abstract}

\section{INTRODUCTION}

Ballistic protection against dynamic loading requires knowledge of body tissue behavior and associated damage mechanisms. Expensive ballistic trials may be minimized via numerical simulations. However, models require material property and calibration data which may only be derived experimentally; availability and ethical considerations mean such experiments normally involve tissue simulants.

Mammalian tissue is highly complex, with a laminated structure involving numerous extended layers, e.g., epidermis, dermis, subcutaneous fat, (adipose tissue) and muscle. ${ }^{1,2}$ Numerous authors have studied the behavior of each of these elements/comparable simulants at low strain rates. For example, Jussila et al. ${ }^{1}$ investigated the response of skin simulants backed by gelatin blocks to impact with lead spheres. They found that $\sim 1 \mathrm{~mm}$ thick chrome-tanned leather exhibited a similar resistance to penetration to human skin. Further, impact with $5.56 \mathrm{~mm} \times 45 \mathrm{~mm}$ federal tactical rounds produced petalled exit wounds similar to those observed with human tissue. Typical subdermal tissue simulants include 10-20 wt. \% gelatin ${ }^{1,3}$ and ballistic soap. While gelatin's viscoelastic behavior mimics human tissue, impact events involving soap result in plastic deformation (cavity formation) equivalent to the peak extent of deformation in gelatin. Shepherd et $\mathrm{al}^{3}{ }^{3}$ employed the impedance-matching technique $^{4}$ to investigate the dynamic response of $20 \mathrm{wt} . \%$ porcine gelatin, with similar behavior to water under shock loading observed for strain-rates $>10^{5} / \mathrm{s}$. Comley and Fleck ${ }^{2}$ employed "trouser tear tests" to investigate the toughness of porcine adipose tissue (a potential human adipose tissue simulant) at strain rates $>1 / \mathrm{s}$. Measured toughness was found to be largely attributable a collagen-based reinforcement membrane surrounding lipid-filled cells (adipocytes), with a minimal contribution from a secondary network of surrounding collagen (known as interlobular septa). In similar work,

\footnotetext{
a) Author to whom correspondence should be addressed. Electronic mail: g.applebythomas@cranfield.ac.uk.
}

Nishioka and Irie $^{5}$ investigated two commercially relevant properties of porcine perirenal fat; "firmness" and "stickiness." Both studies employed an Instron Universal Testing machine with crosshead speeds of $0.2-1.5 \mathrm{~mm} / \mathrm{s}$. Interestingly, adipose material was observed to stretch to a greater extent at higher strain rates.

Impact events often involve strain rates sufficiently high $\left(\geq 10^{5} / \mathrm{s}\right)$ that they overcome the hydrostatic component of the generated stress, leading to hydrodynamic (e.g. fluidlike) behavior. Consequently, knowledge of the hydrodynamic behavior of both projectiles and likely target materials is desirable. As discussed, tissue simulants have predominantly been characterized at low-medium strain rates, with relatively little information on high strain-rate behavior apparent in the literature.

Tissue-based systems exhibit extended three-dimensional structures and will seldom be subject to planar impacts. Some researchers have had success in interrogating such impact conditions. For example, Rosenberg et al. ${ }^{6}$ developed a technique involving the placement of two gauges (of differing type - e.g., manganin and constantan) at a given point within a target to monitor stress evolution with time in axially symmetric systems where the state of strain was not uniaxial. However, as discussed by Field et al., ${ }^{7}$ extension of such work to three-dimensional impacts is nontrivial. Plate-impact experiments, where a one-dimensional state of strain (typically with a strain rate $\geq 10^{6} / \mathrm{s}$ ) is established in a single target material, allow elimination of such complexity. A flat and parallel flyer plate, driven by a compressed gas/powder gun, generates a compressive shock within a target. Inertial confinement allows maintenance of a one-dimensional state of strain until reflections from external edges (release waves) arrive. Instrumentation (e.g., embedded stress gauges) allows shock propagation to be monitored; variables not measured can then be calculated via the Rankine-Hugoniot conservation equations. ${ }^{3,8-10}$ The five shock parameters are: shock velocity, $U_{S}$; continuum mass/particle velocity behind the shock, $u_{P}$; the equilibrium longitudinal (Hugoniot) stress, $\sigma_{X}$; material density, $\rho$, and; 
internal energy, $E$. Hugoniot relationships represented by pairs of these variables (e.g., $U_{S}-u_{P}$ ) describe the physical states a shocked material passes through. Combined with strength data, these Hugoniot relationships allow simulation of the behavior of more complex extended three-dimensional structures under shock.

Here plate-impact experiments ${ }^{3,8,9}$ were employed to investigate the dynamic response of three readily available potential tissue simulants for use in ballistic experiments; namely gelatin, ballistic soap (both subdermal/muscular analogues) and lard (adipose tissue). Embedded manganin stress gauges allowed both derivation of equations-of-state and investigation of lateral strength development under shock.

\section{MATERIALS}

The three tissue analogues investigated were chosen due to their ready availability and similarity to various tissue groups. The human body typically comprises $60-70$ wt. \% water and around $20 \mathrm{wt} . \%$ fat (rest primarily protein, minerals and carbohydrate). ${ }^{3,11,12}$ Gelatin, which suspends water in a solid form suitable for ballistic testing, behaves in an elastomeric manner under impact. An initial large temporary cavity - analogous to the area of peripheral damage around a gunshot wound - subsequently collapses back to a smaller permanent cavity, corresponding to the area of crushed tissue ahead of a penetrating projectile. ${ }^{13} \mathrm{Gel}$ concentrations affect ballistic properties. ${ }^{13}$ Here, a 250 bloom porcine gelatin (Weishardt International, France), was mixed to 25 wt. \% at $\sim 60{ }^{\circ} \mathrm{C}$, with tests conducted at room temperature. ${ }^{3}$ With ballistic soap, permanent plastic cavities of comparable extent to the temporary cavities formed in gelatin targets form under impact. ${ }^{14}$ Soap formation (saponification) involves the hydrolysis of fats or oils in the presence of an alkali such as sodium hydroxide or (for toiletries) potassium hydroxide. Reaction products are a mixture of salts (formed by reaction of excess alkali with carboxylic acids formed in the hydrolysis reaction) and alcohols. ${ }^{15}$ Soaps consist of long-chain backbone structures with active polar "heads." The third material, considered due to its similarity to mammalian adipose layers, was a commercially available fat (manufactured by Matthews Foods plc and retailed by the Co-operative ${ }^{\circledR}$ Food Group as "Fresh Fields Lard"). Such fats possess a complex long-chain structure consisting of glycerol units and attached fatty acids. ${ }^{16}$ Table I summarizes elastic properties, measured ultrasonically using a Panametrics 5077PR pulse receiver in the pulse-echo configuration (sound speeds) and a Micrometrics AccuPyc 1330 gas pycnometer (densities). In all three materials low stiffness made measurement of shear wave speeds $\left(c_{S}\right)$ problematic;

TABLE I. Measured and calculated elastic properties.

\begin{tabular}{lccccc}
\hline \hline & $\rho_{0}(\mathrm{~g} / \mathrm{cc})$ & $c_{L}(\mathrm{~mm} / \mu \mathrm{s})$ & $c_{S}(\mathrm{~mm} / \mu \mathrm{s})$ & $v$ & $\mathrm{~K}(\mathrm{GPa})$ \\
\hline Lard & $0.95 \pm 0.01$ & $1.51 \pm 0.10$ & 0.36 (calc.) & 0.47 (est.) & 2.00 (calc.) \\
Gelatin & $1.06 \pm 0.01$ & $1.48 \pm 0.06$ & 0.33 (calc.) & 0.47 (est.) & 2.17 (calc.) \\
Ballistic & $1.11 \pm 0.00$ & $1.67 \pm 0.07$ & 0.69 (calc.) & 0.40 (est.) & 2.39 (calc.) \\
soap & & & & & \\
\hline
\end{tabular}

consequently, values were calculated from Poisson's ratios $(v)$ using the measured values longitudinal wave speeds $\left(c_{L}\right)$ according to Eq. (1). A value of 0.47 was assumed for both lard and gelatin; based on the assumption that completely incompressible materials would have a Poisson's ratios of 0.5. ${ }^{17}$ However, given the greater stiffness of soap compared to lard and gelatin, a lower value of 0.4 was assumed.

$$
c_{S}=\sqrt{c_{L}^{2} \frac{(0.5-v)}{(1-v)}} .
$$

\section{EXPERIMENTAL}

Plate-impact experiments ${ }^{3,8,9}$ employed a $50 \mathrm{~mm}$ bore single-stage gas-gun to accelerate $\mathrm{Al}$ and $\mathrm{Cu}$ flyer-plates into target materials containing embedded manganin stress gauges manufactured by Vishay Micro-Measurements, USA of types LM-SS-125CH-048 (longitudinal) and J2M-SS580SF-025 (lateral). Longitudinal gauge interpretation followed the impedance matching technique, ${ }^{18}$ with lateral gauge analysis utilizing a modified form that accounted for both the elastic-plastic ${ }^{19}$ and pressure-dependant behavior ${ }^{20}$ of manganin. Inertial confinement ensured a 1D state-ofstrain during impact, with all faces perpendicular to the impact axis finished to a tolerance of $\leq 5 \mu \mathrm{m}$. A typical experimental arrangement is presented in Fig. 1, with the lateral configurations employed detailed in Fig. 2. Due to the difficulty associated with machining soft materials, targets were cast in-situ into pre-prepared target assemblies with front faces machined to the tolerances detailed above., ${ }^{3,21}$ Where lateral gauges were employed these were pre-encapsulated in (typically) $50 \mathrm{~mm}$ Mylar and clamped between two mating surfaces of a prepared sectioned confinement ring. This arrangement was then fronted by a pre-machined cover plate, with the required target material then cast around the gauge. This procedure is discussed in more detail for lard by Wilgeroth et al., ${ }^{21}$ while general plate-impact

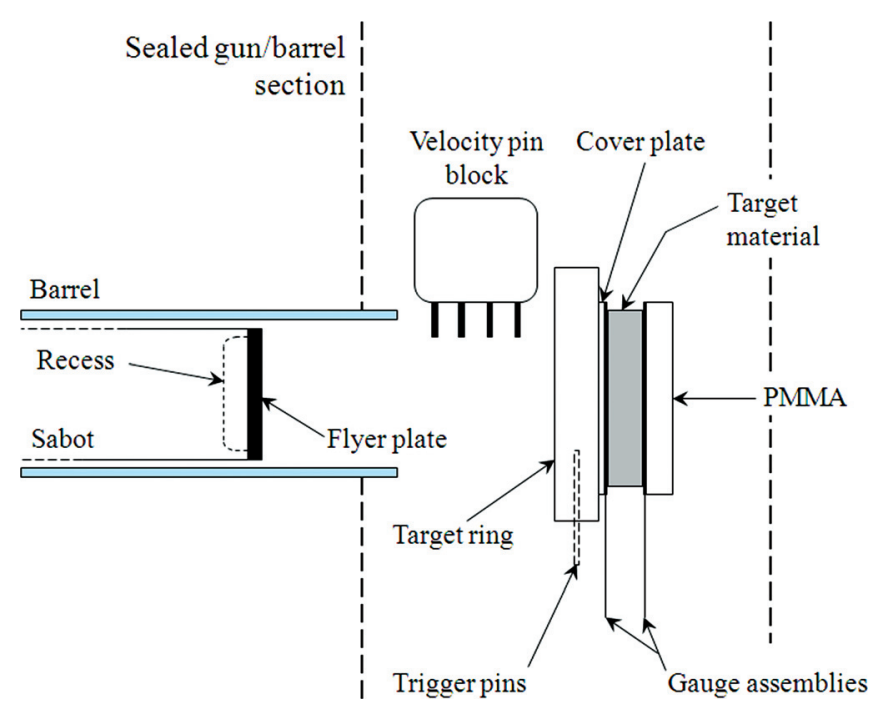

FIG. 1. (Color online) Typical plate-impact experimental arrangement; longitudinal gauge assemblies encapsulated by $25-\mu$ m-thick Mylar. 


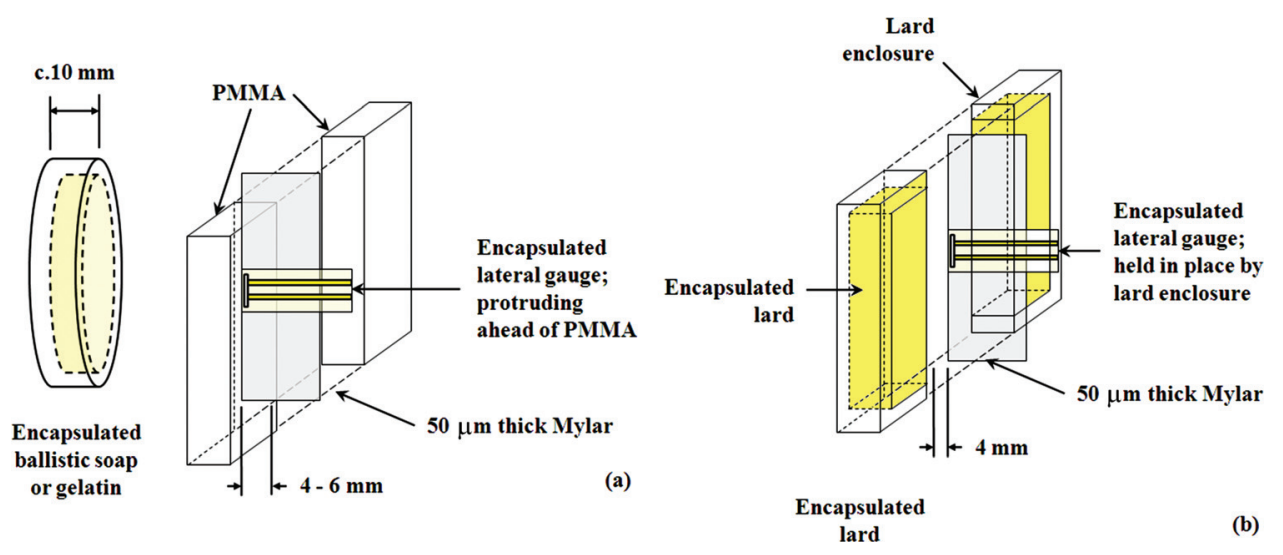

FIG. 2. (Color online) Lateral gauge mounting configurations: (a) ballistic soap and gelatin; (b) lard. Arrangements fronted by a $1-\mathrm{mm}$-thick $\mathrm{Al}$ or $\mathrm{Cu}$ cover plate to ease target material casting, before assembly following Fig. 1 (not to scale). setup following target assembly followed a standardized procedure detailed elsewhere. ${ }^{8,9}$

\section{RESULTS AND DISCUSSION}

Figure 3 shows typical longitudinal gauge traces for all three materials. Processing was limited to conversion of measured voltages to stress, with rear-surface traces rescaled according to Eq. (2). Slight discrepancies between the front and corrected rear-surface Hugoniot stress amplitudes -labeled (c) in Fig. 3 - likely arose because Eq. (2) is intended for use in strong-shock hydrodynamic (fluid) systems, whereas here strength effects are apparent. Nevertheless, the good agreement between front and rear-surface traces in all cases appears to justify its application here.

$$
\sigma_{\text {target-material }}=\frac{1}{2} \frac{\left(Z_{\text {target}- \text { material }}+Z_{\mathrm{PMMA}}\right)}{Z_{\mathrm{PMMA}}} \sigma_{\mathrm{PMMA}}
$$

where $\sigma_{n}$ and $\mathrm{Z}_{n}$ are the stress and impedance $\left(\rho_{0} U_{s}\right)$ in material " $n$ ", respectively.

Several features are common in all cases, namely: (a) a rapid $\sim 100$ ns rise on shock arrival, indicative of good alignment and a close impedance match with the encapsulating Mylar; (b) an overshoot in stress, linked elsewhere to electrical ringing within the gauge packet; ${ }^{8,9,22}$ (c) a relatively flat plateau following shock arrival (the Hugoniot stress); (d) a two-stage elastic-plastic unloading following arrival of release waves from the rear of the flyer plate, and; (e) eventual gauge failure. For both gelatin and lard lower shock impedances than the PMMA backing result in reloading before release arrival. Finally, when combined with knowledge of target thickness, the temporal separation between the front and rear-surface traces $-\Delta t$ in Fig. 3(b) - allowed calculated of $U_{S}$. Hugoniot equations-of-state in the shock velocity-particle velocity $\left(U_{S^{-}} u_{P}\right)$ and pressure-volume $(P-v$, where $v=1 / \rho$ ) planes are shown in Figs. 4(a) and 4(b), respectively. In both cases hydrodynamic curves are

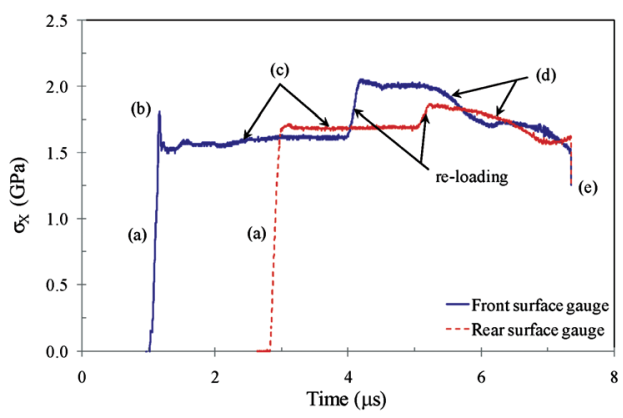

(a) $4.6 \mathrm{~mm}$-thick gelatin target impacted by a $10 \mathrm{~mm}$ thick $\mathrm{Cu}$ flyer at $604 \mathrm{~m} / \mathrm{s}$

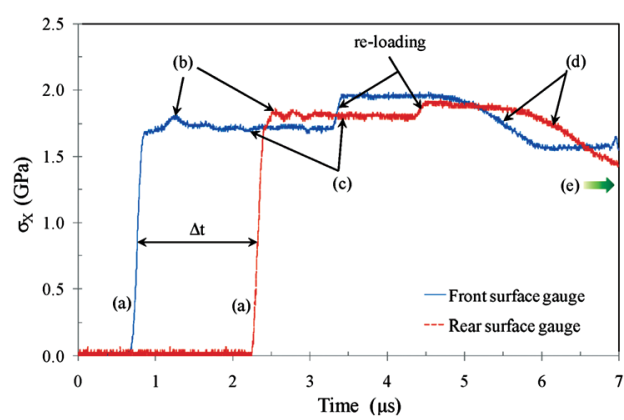

(b) $4.5 \mathrm{~mm}$-thick ballistic soap target impacted by a $10 \mathrm{~mm}$-thick Cu flyer at $524 \mathrm{~m} / \mathrm{s}$
FIG. 3. (Color online) Typical longitudinal gauge traces.

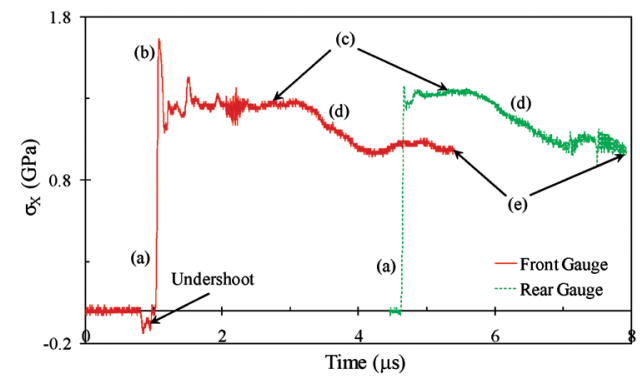

(c) $9.9 \mathrm{~mm}$-thick lard target impacted by a $5 \mathrm{~mm}$-thick Cu flyer at $489 \mathrm{~m} / \mathrm{s}$ 


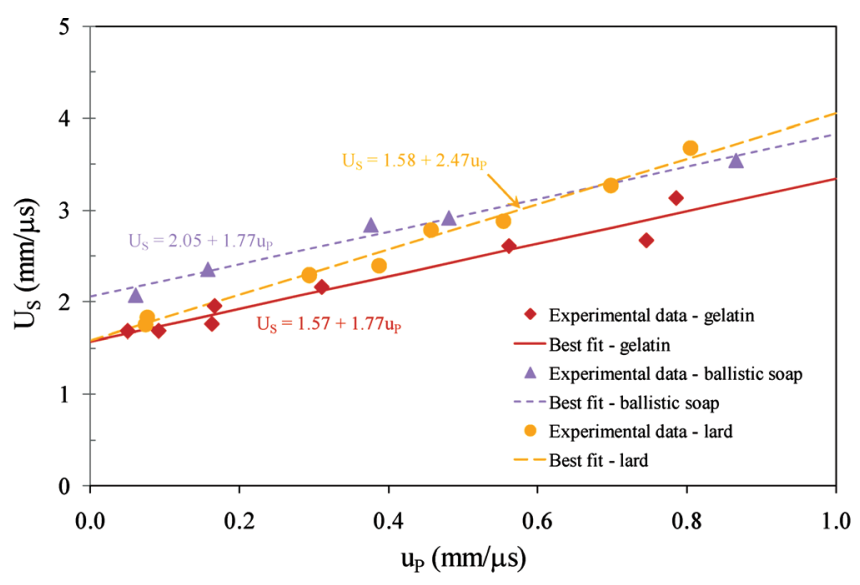

(a) $U_{S}-u_{P}$

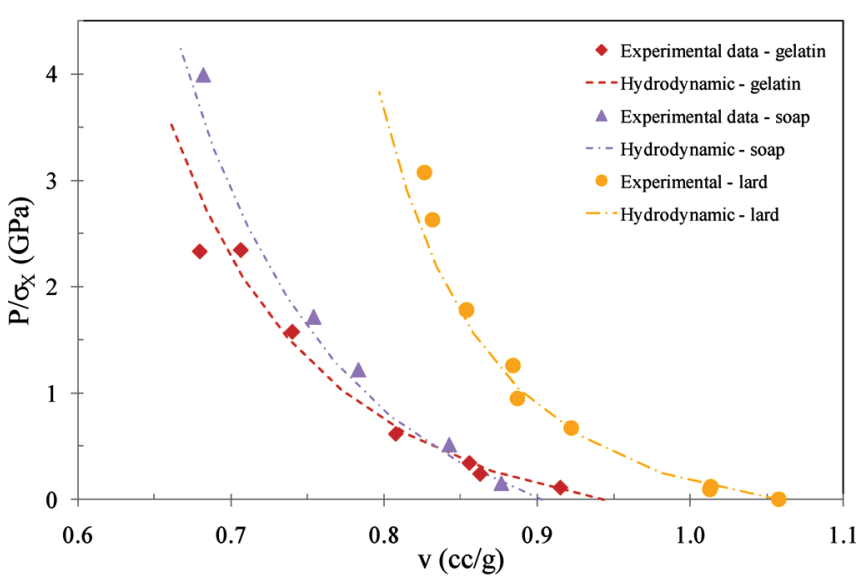

(b) P-V

FIG. 4. (Color online) Hugoniot relationships for gelatin, ballistic soap and lard.

included for each material calculated according to Eqs. (3) and (4). ${ }^{10}$

$$
\begin{gathered}
P=\rho_{0} U_{S} u_{P}=\rho_{0}\left(c_{0}+S u_{P}\right) u_{P} \\
v=v_{0}\left[\frac{U_{S}-u_{P}}{U_{S}}\right]=v_{0}\left[\frac{\left(c_{0}+S u_{P}\right)-u_{P}}{\left(c_{0}+S u_{P}\right)}\right],
\end{gathered}
$$

where $v=1 / \rho=$ volumetric density and $v_{0}=$ initial volume $\left(1 / \rho_{0}\right)$.

All materials exhibited linear $U_{S}-u_{P}$ equations-of-state of the form $U_{S}=c_{0}+S u_{P}$. Values for the slope $(S)$ and the intercept $\left(c_{0}-\right.$ essentially the materials' bulk sound speed) are included in Fig. 4(a). Interestingly, lard and gelatin both exhibit similar bulk sound speeds to water $^{23}(1.58,1.57$ and $1.45 \mathrm{~mm} / \mu \mathrm{s}$, respectively), suggesting similar shock response at nominal particle velocities. The magnitude of $S$ correlates to the first pressure derivative of the bulk modulus, ${ }^{24-26}$ meaning higher values correspond to greater compressibility. Figure 4(a) therefore suggests that lard is more compressible than soap and gelatin ( $S$ equal to $2.47,1.77$, and 1.77 , respectively). The low compressibility of gelatin seems reasonable as, like a fluid, ${ }^{26,27}$ under quasistatic conditions it does not appear to support a shear wave. ${ }^{3}$ Interestingly, soap appears to exhibit a similar resistance to compression to gelatin - suggesting that the presence of its polar side groups acts to resist compression. Conversely, the (apparent) enhanced compressibility of lard is likely attributable to the ability of its polymer-like molecules to deform under compression. Figure 4(a) suggests that interaction between the glycerol units/attached fatty acids comprising lard offers less resistance to compression than that between the soap's (carboxylic acid) salts (such resistance to compression may be due to steric effects, ${ }^{26,28-33}$ or alternatively, in the case of the soap, repulsion between polar side groups could potentially be a contributing factor).

All three materials initially follow their respective $P-v$ plane hydrodynamic curves. However, at elevated pressures ballistic soap and lard deviate from the hydrodynamic response. Eq. (5) relates the hydrodynamic pressure $(P)$ to longitudinal stress and the maximum shear strength $\left(\tau_{\max }\right)$ of the material. ${ }^{9}$ Consequently, the deviation in stress above the hydrodynamic curve in Fig. 4(b) may be attributed to an increase in material shear strength. The extent of deviation from the hydrodynamic response appears to increase with impact pressure in both lard and soap (interestingly, while less marked, in the case of the soap deviation appears to begin at lower pressures than in the lard). From Eq. (5), this behavior suggests that shear strength increases with impact pressure. Such behavior in polymeric materials has been linked elsewhere to the previously highlighted phenomenon of steric interference. $^{26,28-30}$ Essentially, the greater the polymeric side-group complexity, the higher the apparent resistance to compression (e.g., lard and soap here, although in the latter case, repulsion between polar side groups may also be a factor). It should be noted that in addition to the steric-based model discussed above, ${ }^{26,28-30}$ other theories regarding the high strain-rate response of polymeric materials have been postulated. In particular, Porter and Gould ${ }^{34}$ have developed a molecular-level technique known as group interaction modeling. This approach, based on knowledge of the potential which exists between polymer chains and the heat capacity (derived from the vibrational frequencies of polymer chains), allows derivation of the pressure-dependant continuum polymer response. Good agreement has been shown with experimental data in the $U_{S}-u_{P}$ plane, with experimentally observed curvatures in the Hugoniot at low particle velocities for many polymeric materials closely replicated. Further, recent extensions of the group interaction model have suggested that it might be extended to allow for the interaction between differing side groups. ${ }^{35,36}$ Consequently, while not directly considered in the interpretation of material behavior here, in the future this approach may potentially provide a route to numerically predict steric effects.

$$
P=\sigma_{x}+\frac{4}{3} \tau_{\max }
$$

Figure 5 shows typical gelatin, ballistic soap and lard lateral stress profiles. In all cases the initial rise on shock arrival leads to an overshoot in stress (again, attributed to ringing in the gauge). The trace for the gelatin is relatively smooth; following an initial plateau with a gradient of $-0.03 \mathrm{GPa} / \mu \mathrm{s}$, a small decrease in stress at $\sim 2.5$ micro-seconds leads to a 


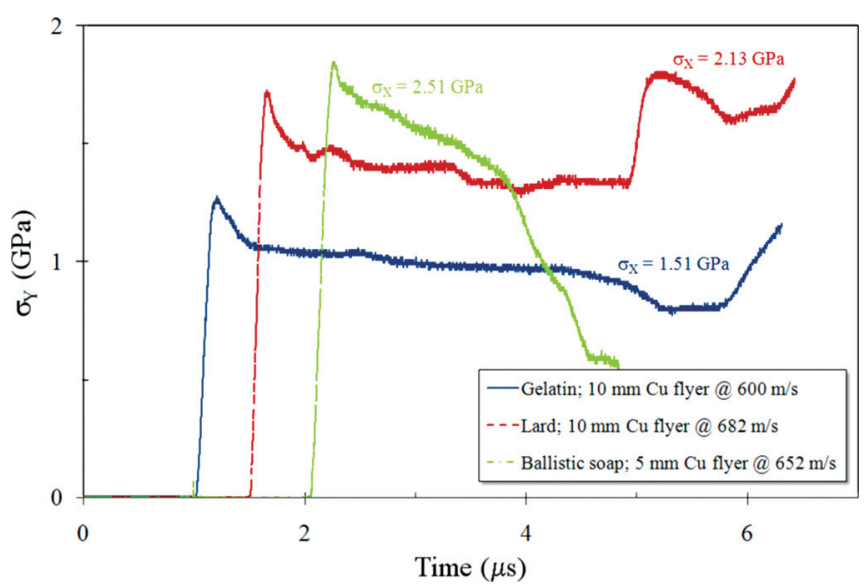

FIG. 5. (Color online) Typical lateral gauge traces (offset by $0.5 \mu \mathrm{s}$ ) for gelatin, lard, and ballistic soap.

longer secondary plateau whose gradient is just $-0.01 \mathrm{GPa}$ / $\mu \mathrm{s}$. The test is ended by the arrival of release waves from the rear of the flyer. Following shock arrival, the lard trace is significantly noisier than the gelatin response; further, reflections from the backing PMMA lead to a reloading after $\sim 3.5$ $\mu \mathrm{s}$, before release arrival. Again, individual plateaus are apparent; however over the initial overshoot to reloading data range, a gradient of $-0.05 \mathrm{GPa} / \mu$ s results, compared to $-0.03 \mathrm{GPa} / \mu$ s overall for gelatin. With the ballistic soap, however, the lateral response is substantially different. Postovershoot, following a very short duration $(>0.05 \mu \mathrm{s})$ plateau, a consistent negative gradient of $-0.266 \mathrm{GPa} / \mu \mathrm{s}$ results; very much greater than for gelatin or lard. Finally, faster release arrival occurs due to the use of a 5 rather than $10 \mathrm{~mm}$ thick flyer.

Equation (6) links lateral and longitudinal stress to shear strength $(\tau)$. Assuming constant longitudinal stresses behind the shock (Fig. 3), the observed decreases in lateral stress in Fig. 5 suggest an increase in strength with time.

There is, however, substantial controversy over the interpretation of lateral gauge response behind the shock. In particular, perceived changes in strength behind the shock have been linked to shock dispersion between the lateral encapsulation and target material. ${ }^{37,38}$ However, recent work by Appleby-Thomas et al. $^{39}$ has implied that such effects are minimal in polymers where encapsulation/material sound speeds are similar. Further, in this study gauges were cast in situ $^{21}$ consequently in most cases only $\sim 2 \mathrm{~mm}$ of Mylar ${ }^{\circledR}$ lay ahead of the gauge elements. While recent in-house work (not included here) suggests such localized encapsulation may reduce the magnitude of gradients by up to $0.02 \mathrm{GPa} /$ $\mu \mathrm{s}$, such changes are insufficient to affect the overall trends apparent in Figs. 5 and 6 (introduced below). Consequently, estimation of shear strengths from measured lateral stresses is adopted here, with any changes in lateral stress behind the shock measured as conservatively as possible.

The small post-shock-arrival gelatin gradient in Fig. 5 suggests little strengthening — consistent with the apparent hydrodynamic response in Fig. 4(b). However, the substantial difference in gradients for lard and soap in Fig. 5, despite broadly similar impact conditions, suggests substantially

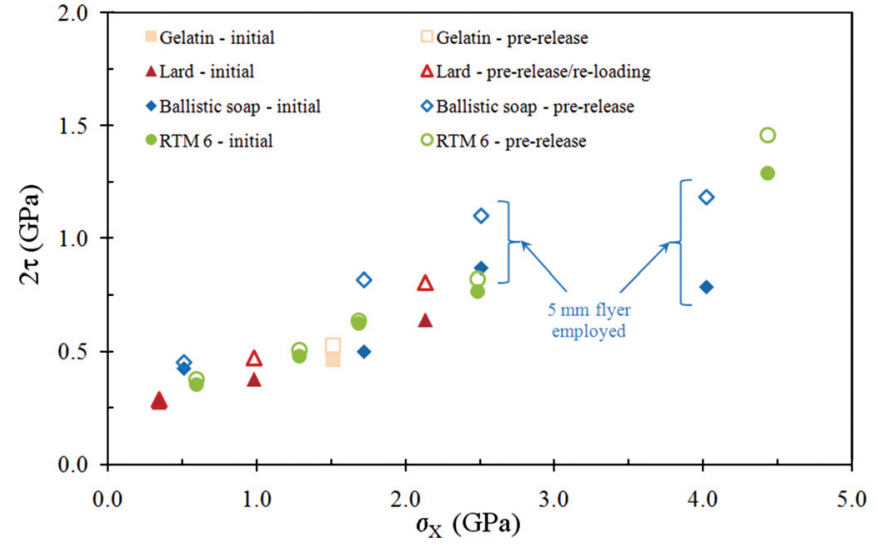

FIG. 6. (Color online) Variation of shear strength with impact stress for gelatin, lard, ballistic soap, and RTM 6 (Ref. 9).

greater strengthening in ballistic soap. While only one lateral test was carried out with gelatin, several were conducted with both lard and ballistic soap. Shear strengths, shown in Fig. 6, were calculated based on $\sigma_{Y}$ values measured both following any initial overshoot in lateral stress and just prior to reloading/release arrival. Constant Hugoniot stress values were assumed, where required calculated from a best-fit to the relevant measured (rather than hydrodynamic) curves in Fig. 4. For clarity no error bars are included; typical errors in shear strength were $\pm 5 \%$. Furthermore, similar data for a commercial grade aerospace epoxy resin (RTM 6) is included ${ }^{9}$ for comparison.

$$
2 \tau=\sigma_{X}-\sigma_{Y}
$$

There are a number of key points to note from Fig. 6. First, a material-independent (nominally polynomial) increase in shear strength with impact stress is apparent. This suggests the operation of similar strengthening mechanisms, unlike the material-dependant hardening apparent in Fig. 4(b). It is postulated that this strengthening on shock arrival arises due to re-arrangement of amorphous polymer-like chains/molecules. Second, at any particular impact stress the difference between the shear strength at the beginning and end of the lateral stress profile (essentially another expression of the difference in gradients apparent in Fig. 5) is material dependant. E.g., at ca. 2.5 GPa this difference in shear strengths is significantly greater for soap than RTM 6-despite the use of 5 $\mathrm{mm}$ rather than $10 \mathrm{~mm}$ thick flyers with the soap. This suggests a material-specific response. Such behavior seems similar to that observed previously where greater hardening both on $^{30}$ and following ${ }^{26,28,29}$ shock arrival was found to correlate with the scale of side-group structures in polymeric materials. Here, the ionic long chain carboxylic acid salts present in the soap appear to lead to a greater degree of intermolecular interaction under compression. In turn, this suggests that the lard's nonpolar glycerol units/attached fatty acids are likely more complex than RTM 6 (Ref. 9) (itself more complex than gelatin). The disparity between initial and pre-release/reloading shear strengths in Fig. 6 is observed to increase in magnitude in line with this proposed evolution in microstructural complexity —enhancing the notion that such behavior 
behind the shock is attributable to steric hindrance. ${ }^{26,28-30}$ Interestingly, this behavior broadly matches the previously discussed correlation between $S$ and compressibility in Fig. 4(a), with soap again showing greater apparent resistance to compression (hardening) than lard.

\section{CONCLUSIONS}

Linear $U_{S}-u_{P}$ equations-of-state have been established for gelatin, ballistic soap and lard (over a limited pressure range), with compressibility linked to the slope of the (experimental) linear best-fits. Evidence of apparent strengthening under shock observed for both lard and ballistic soap in the $P-v$ plane was tentatively attributed to a steric hindrance effect.

Furthermore, embedded lateral gauges were used to investigate shear strength both at, and following, shock arrival. While the controversial nature of this approach was highlighted, its application here was considered justifiable, primarily because gauges were cast in-situ, with minimal encapsulating material ahead of the gauge. In particular, comparable target material/local encapsulation (e.g., Mylar $^{\circledR}$ ) shock velocities meant that shock dispersion would be minimal. Gradients in lateral stress appeared to suggest strengthening under shock - again tentatively attributed to steric hindrance. However, while shear strength behavior behind the shock appeared material-dependant, its overall magnitude appeared to increase with impact stress independent of the target material. It was postulated that this was a structural effect, with polymer-like molecular chains compressing at a constant rate on shock arrival before steric hindrance effects came into play behind the shock.

\section{ACKNOWLEDGMENTS}

Dr. Derek Allsop (Cranfield University) and ARUP are gratefully acknowledged for scientific and financial support respectively. Additionally, Gareth Appleby-Thomas would like to thank his wife, Caroline Jane Appleby-Thomas, for support during the production of this paper.

${ }^{1}$ J. Jussila, A. Leppäniemi, M. Paronen, and E. Kulomäki, Forensic Sci. Int. 150, 63 (2005).

${ }^{2}$ K. Comley and N. A. Fleck, J. Biomech. 43, 1823 (2010).

${ }^{3}$ C. J. Shepherd, G. J. Appleby-Thomas, P. J. Hazell, and D. F. Allsop, in Proceedings of the American Physical Society Topical Group on Shock Compression of Condensed Matter, edited by M. L. Elert, W. T. Buttler, M. D. Furnish, W. W. Anderson, and W. G. Proud (AIP, Melville, New York, 2009), p. 1399.

${ }^{4}$ Ya. B. Zel'dovich and Yu. P. Raizr, Physics of Shock Waves and HighTemperature Hydrodynamic Phenomena, edited by W. D. Hayes and R. F. Probstein (Dover, New York, 2002).

${ }^{5}$ T. Niskioka and M. Irie, Meat Sci. 70, 399 (2005).
${ }^{6}$ Z. Rosenberg, Y. Partom, M. Mayseless, and J. Falcovitz, J. Appl. Phys. 56, 1434 (1984).

${ }^{7}$ J. E. Field, S. M. Walley, W. G. Proud, H. T. Goldrein, and C. R. Siviour, Int. J. Impact Eng. 30, 725 (2004).

${ }^{8}$ G. J. Appleby-Thomas, P. J. Hazell, C. Stennett, G. Cooper, K. Helaar, and A. M. Diederen, J. Appl. Phys. 105, 064916 (2009).

${ }^{9}$ G. J. Appleby-Thomas, P. J. Hazell, and C. Stennett, J. Mater. Sci. 44, 6187 (2009).

${ }^{10}$ M. A. Meyers, Dynamic Behavior of Materials (Wiley, New York, 1994).

${ }^{11}$ A. J. Gaudin, K. C. Jones, J. G. Cotanche, and J. Ryan, Human Anatomy and Physiology (Harcourt Brace Jovanovich, San Diego, 1989).

${ }^{12}$ W. Shen, Z. Wang, M. Punyanita, J. Lei, A. Sinav, J. G. Kral, C. Imielinska, R. Ross, and S. B. Heymsfield, Obesity Res. 11, 5 (2003).

${ }^{13}$ N. C. Nicholas, and J. R. Welsch, Institute for Non-Lethal Defense Technologies Report: Ballistic Gelatin (Applied Research Laboratory, The Pennsylvania State University, 2004).

${ }^{14}$ G. N. Rutty, P. Boyce, C. E. Robinson, A. J. Jeffery, and B. Morgan, Int. J. Legal Med. 122, 1 (2008).

${ }^{15}$ G. G. Hill and J. S. Holman, Chemistry in Context (Nelson \& New York, 1978).

${ }^{16}$ B. R. Mackenna and R. Callander, Illustrated Physiology (Churchill Livingstone, New York, 1990).

${ }^{17}$ F. Kallel and M. Bertrand, IEEE Trans. Med. Imaging 15, 299 (1996).

${ }^{18}$ Z. Rosenberg, D. Yaziv, and Y. Partom, J. Appl. Phys. 51, 3702 (1980).

${ }^{19}$ Z. Rosenberg and N. S. Brar, J. Appl. Phys. 77, 1443 (1995).

${ }^{20}$ J. C. F. Millett, N. K. Bourne, and Z. Rosenberg, J. Phys. D: Appl. Phys. 29, 2466 (1996)

${ }^{21}$ J. M. Wilgeroth, P. J. Hazell, and G. J. Appleby-Thomas, J. Appl. Phys. 108, 093527 (2010).

${ }^{22}$ P. J. Hazell, C. Stennett, and G. Cooper, Polym. Compos. 29, 1106 (2008).

${ }^{23}$ K. Nagayama, Y. Mori, Y. Motegi, and M. Nakahara, in Shock Compression of Condensed Matter, edited by M. D. Furnish, M. Elert, T. P. Russell and C. T. White (AIP, Melville, New York, 2005), p. 1547.

${ }^{24}$ L. Davison and R. A. Graham, Phys. Rep. 55, 255 (1979).

${ }^{25}$ J. C. F. Millett, N. K. Bourne, Y. J. E. Meziere, R. Vignjevic, and A. Lukyanov, Compos. Sci. Technol. 67, 3253 (2007).

${ }^{26}$ N. K. Bourne, and J. C. F. Millett, Metall. Mater. Trans. A 39A, 266 (2008).

${ }^{27}$ F. M. White, Fluid Mechanics (McGraw Hill, New York 1979).

${ }^{28}$ J. C. F. Millett, G. Whiteman, S. M. Stirk, and N. K. Bourne, in Society for Experimental Mechanics - SEM Annual Conference and Exposition on Experimental and Applied Mechanics (Curran Associates Inc., Red Hook, New York, 2009), p. 498.

${ }^{29}$ N. K. Bourne and J. C. F. Millett, J. Mater. Sci. 43, 185 (2008).

${ }^{30}$ J. C. F. Millett and N. K. Bourne, J. Phys. D: Appl. Phys. 37, 2901 (2004).

${ }^{31}$ J. C. F. Millett and N. K. Bourne, Steric Effects in Organic Chemistry, edited by M. S. Newman (Wiley, New York, 1956).

${ }^{32}$ R. J. Young, Introduction to Polymers (Chapman and Hall, London, 1981).

${ }^{33}$ C. E. Housecroft and E. C. Constable, Chemistry: An Introduction to Organic, Inorganic and Physical Chemistry, $3^{\text {rd }}$ ed. (Pearson Education Ltd., Harlow, UK, 2006).

${ }^{34}$ D. Porter and P. J. Gould, J. Phys. IV 134, 373 (2006).

${ }^{35}$ J. P. Foreman, D. Porter, S. Behzadi, and F. R. Jones, Polymer 49, 5588 (2008).

${ }^{36}$ J. P. Foreman, D. Porter, S. Behzadi, P. T. Curtis, and F. R. Jones, Composites, Part A 41, 1072 (2010).

${ }^{37}$ R. E. Winter and E. J. Harris, J. Phys. D: Appl. Phys. 41, 035503 (2008).

${ }^{38}$ R. E. Winter, G. D. Owen, and E. J. Harris, J. Phys. D: Appl. Phys. 41, 202006 (2008).

${ }^{39}$ G. J. Appleby-Thomas, P. J. Hazell, J. M. Wilgeroth, and D. C. Wood, J. Appl. Phys. 108, 033524 (2010). 